\title{
Endoscopic Ultrasound
}

National Cancer Institute

\section{Source}

National Cancer Institute. Endoscopic Ultrasound. NCI Thesaurus. Code C46078.

An ultrasound administered by using a tube containing flexible fibre optic wires that allows for the analysis of tissues inside the body. Ultrasound technology utilizes high frequency waves and their echoes to produce an image. 2005 